\title{
Planetary Urbanisation and the Built Heritage from a Non-Western Perspective: The Question of 'How' We Should Protect the Past
}

\author{
Giulio Verdini \\ Department of Planning and Transport, University of Westminster, United Kingdom \\ Email: g.verdini@westminster.ac.uk
}

\begin{abstract}
The process of planetary urbanisation, which is currently affecting a large part of the world, impacts on the existing built environment in an unprecedented way. Its dramatic rapidity often implies the sudden disappearance of traditional urban and rural structures and the rapid transformation of local cultures. Contextually, as never before, attempts to protect culture in its tangible and intangible expressions are increasingly central to international agendas on sustainable urbanisation. However, this is by no means an easy task to achieve. The main reason for the controversy is that the consensus around the need to protect heritage and its tools, as formulated primarily in the Western world in the past, has changed. It has been challenged by alternative, non-Western, primarily non-materialistic views, or it has been delegitimised by the (often) exploitative practice of heritagisation, as a result of the process of protection itself. The main aim of this paper is to reflect on the implications of contemporary planetary urbanisation on the built heritage and its protection, considering that most of this process is taking place in fast-developing countries of Asia, Africa and South America and, at the same time, there is a redistribution of economic (and therefore cultural) power from the West to the East, and from the North to the South of the planet.
\end{abstract}

KEYWORDS planetary urbanisation, urban theory, built heritage, urban conservation, non-Western, material vs immaterial, community

Received July 6, 2017; accepted August 19, 2017.

\section{Culture in the Urban Age. What We Should Protect?}

Over previous decades, urbanisation has increased dramatically, especially with the contribution of the so-called global South, and its pace is not deemed likely to slow down soon. UN projections foresee that countries such as China, India, and Nigeria, alone, will generate almost $37 \%$ of the total projected urban growth population till 2050; this number is now estimated as 2.5 billion people, with nearly $90 \%$ of the increase concentrated in Asia and Africa (United Nations 2015a). Despite the controversial interpretation of this process, as will be reported in the next section, this generates concern for its overall sustainability. Topics such as the impact of urbanisation on environment and climate change, the overall sustainability of cities and the current large migration process, both domestic and transnational, have deeply informed the ethos of the UN 2030 Agenda for sustainable development (United Nations 2015b).

The existing built environment and its communities are deeply affected by the urbanisation process, with the result that local cultures are being drastically adapted, transformed and sometimes forcibly moved elsewhere. The transformation of Chinese cities, with large-scale demolition of inner-city historic areas and relocation of local people, have probably contributed more than other examples to this narrative, and fomented this global discourse. For instance, the demolition of dilapidated innercity neighbourhoods in Beijing started in the 1990s (Zhang and Fang 2004), and culminated in the Olympic Games of 2008, whereby the traditional hutong area near the Forbidden City was largely torn down and the rest submitted to rapid gentrification (González Martínez 2016) (Figure 1a, Figure $1 b$ ). This is also a common trait in other countries. 

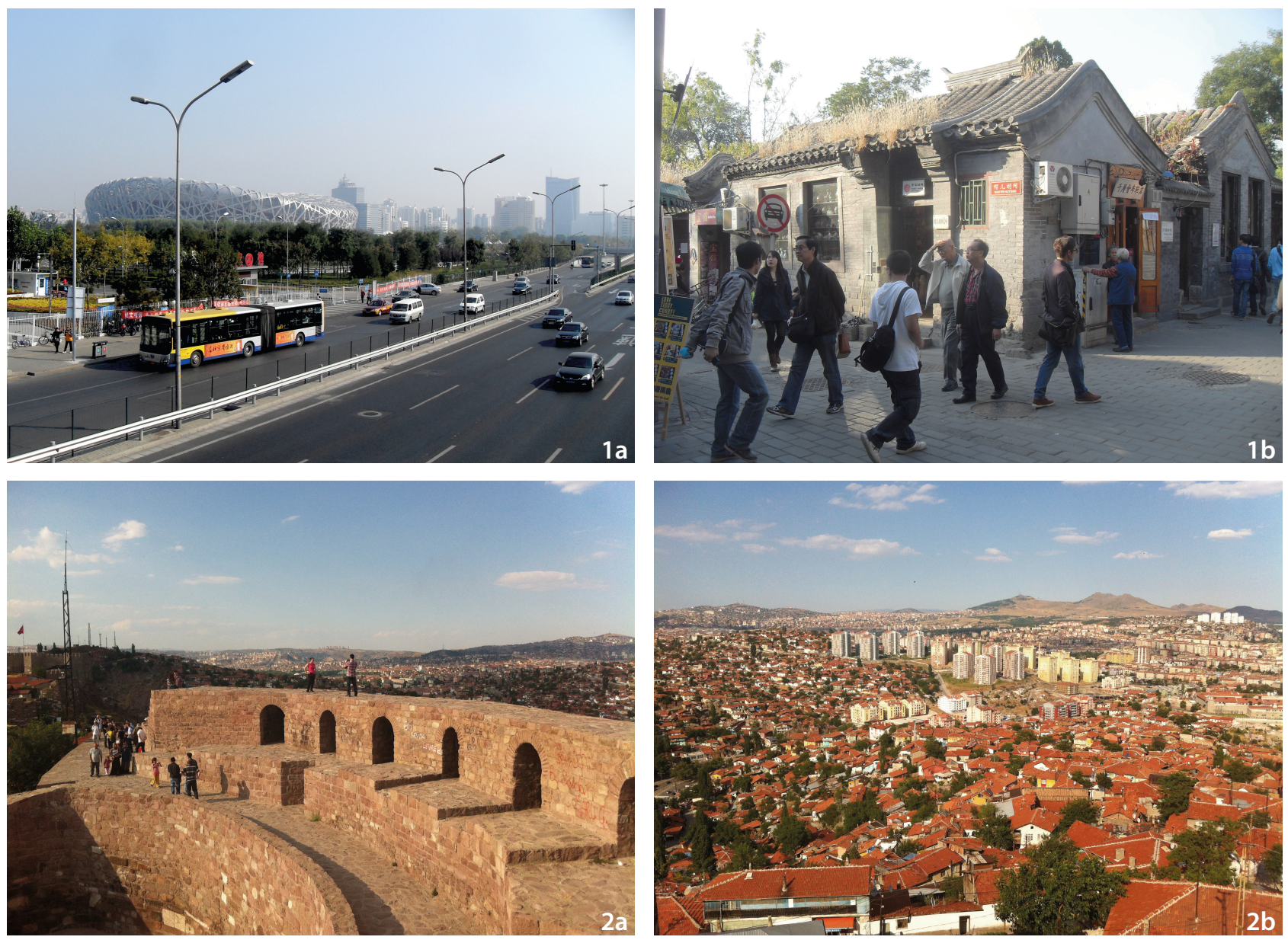

Figure 1a and 1b Beijing, People's Republic of China. The Olympic Games area and the remained traditional hutongs now mainly transformed into commercial streets (Source: the author).

Figure 2a and 2b Ankara, Turkey, 2012. The Hisar fortress of Ulus district and the surrounding view on modern residential compounds (Source: the author).

For example, new real estate developments have suddenly appeared in and around the old city centre of Beirut in Lebanon (Yassin 2012), replacing the old French colonial houses of Ho Chi Minh in Vietnam (Clark 2011) and have dramatically altered the low-density, historic urban landscape of Ankara in Turkey (Batuman 2013) (Figure 2a, Figure 2b).

Local communities, on the other hand, are no longer relatively homogenous components of modern nation states: 'The many displaced, deterritorialised, and transient populations that constitute today's ethnoscapes are engaged in the construction of locality, as a structure of feeling, often in the face of the erosion, dispersal, and implosion of neighbourhoods as coherent social formations.' (Appadurai 1996, 199) Changing localities, and their cultural features, are dependent on both (tangible) mass migration and (intangible, although even more pervasive) 'mass-mediated images, script and sensations' (4) leading Appadurai to argue that 'the valuable feature of the concept of culture is the concept of difference, a contrastive rather than a substantive property of certain things' (12).

European historic centres, after the Second World War, were surely more socially coherent than today. Cities, culture and cultural heritage were the expression and representation of national identities. This situation has literally turned upside down, challenging the idea of coherence and 'harmonious adaptation to contemporary life', which has long been associated with the authenticity of a place (ICOMOS 1987).

This process of rapid transformation involves both the gentrified neighbourhoods of central London, purchased en masse by Middle Eastern and Chinese buyers, or the relatively deprived historic areas of the developing world. It is very common in China, where the historic inner areas of cities such as Shanghai, Suzhou and Nanjing, despite their traditional appearance, host a population of newcomers, primarily composed of new urban elites or, still the majority, domestic rural migrants (Verdini 2015). 
Rapid cultural hybridisation happens even in once-rural and more isolated areas, such as small towns in the south of Italy and Greece, hosting refugees and economic migrants coming from across the Mediterranean.

UNESCO, among international UN agencies, has been globally at the forefront in raising international attention on the need to protect cultural heritage and local cultural diversity worldwide. Its focus has shifted from the specific conservation of cultural and natural heritage to the protection of urban heritage, historic urban landscapes and diversity of cultural expression. Very recently, UNESCO has also promoted the first global survey on the role of culture for sustainable urban development, which has been instrumental in advocating globally the need to place culture at the core of urban policy and presented at the UN Habitat III Conference in Quito in October 2016 as a contribution to the 'New Urban Agenda' 2016-2036 (UNESCO 2016). Being probably the most comprehensive survey today on culture in the 'urban age' and promoting advocacy for its protection, it provides a comprehensive catalogue of cases where culture, creativity and cultural heritage are protected and managed across the world (see the eight study areas in part A of the Report, p. 26 and the final 'Atlas', p. 272).

Nevertheless, the Global Report, despite being a powerful and useful overview of 'what we should protect' (and indeed of what is already protected), opens up also several unresolved questions. These are related to the impact that planetary urbanisation has, and will have, for the built heritage and for local cultures in the years to come, and what this might mean for the current doctrine of conservation. The intention therefore is to situate the debate as to the protection of the past within the discussion of massive and rapid urbanisation. The question of 'how' we should protect will then be supported by a critical inquiry into the changing conditions of contemporary time, to assess whether the tools available for the protection of the past are still valid today.

\section{Planetary Urbanisation and Whether It Matters for the Built Heritage}

Over the last decade there has been a remarkable attempt to reposition the field of urban studies and its theoretical foundations in the light of the undeniable process of massive urbanisation of the planet. This process has been generally understood as a shift of residents from rural to urban areas, thus justifying the label of 'urban age' to describe it, among international agencies and academic scholars (Burdett and Rode 2010). This process, moreover, has been widely associated with cultural homogenisation and even destruction of the past, mobilising resources and fostering advocacy for reversing this trend (UNESCO 2016). However, this statistical evidence has not generated consensus on the interpretation of the 'urban age', in primis because data to measure urbanisation have been often used improperly (Satterthwaite 2010), and, most importantly, because it has not been theoretically supported by novel approaches and methods, capable of capturing the complexity of the process of urbanisation at the global scale (Brenner and Schmid 2014).

Interestingly, in attempts to address this gap, two main, conflicting streams have emerged. On the one hand are those who have attempted to retain a degree of universalism in addressing the needs of a suitable urban theory for such massive urbanisation (Scott and Storper 2014) and, on the other, those who, instead, have 'provincialised' this effort by looking at the functioning of nonWestern cities (Robinson 2006; Roy 2011). These divergencies find an interesting parallelism with the current debate around the built heritage, as will be described later.

In the former case, Scott and Storper (2014, 9-11) have insisted 'on the distinction between issues that are to be found in cities but that are not intrinsically urban in character and issues of cities' which 'revolve around processes of agglomeration cum polarisation and associated interactions within the urban land nexus'. In retaining the notions of agglomeration, polarisation and the struggle for scarce land as a common ground and a generalised analytical paradigm of cities everywhere, they identify 'contextual variables', among them the fact that a 'source of difference stems from cultural norms and traditions. These affect a multitude of practices and ways of life that affect the urban landscape, including the formation, evolution and persistence of neighbourhoods and the operation of local labour markets'.

Comparative urbanism, instead, as a result of postcolonial critical studies, has been instrumental in challenging the idea of unifying principles by tracing a line between 'global' and 'universal' (Robinson 2016). While urbanisation, as manifestation of the capitalist system of production, is 'undeniably global, the universality of such process is another matter' (Roy, 2016), proved for example by 'the persistence of economic informality, multiplicity, marginality and dispersion, and not agglomerations' in many Southern cities (Parnell and Pieterse 2016).

While both contributions offer convincing analytical frameworks to readjust or directly challenge the global discourse of the 'urban age' as put forward by UN 
agencies, they are far from being reconciled (Roy 2016). The former approach, being rooted in economic analysis, offers a convenient, yet functionalist, shortcut to simplify a variety of international cases, which surely appears quite unmanageable. The latter, being rooted in critical social theory, offers instead an appealing horizon for action from a non-Western and post-colonial perspective.

For the scope of this article, the two will both be considered plausible and discussed from the perspective of the built heritage. The intention here is not to raise an epistemological discussion on the nature of the 'urban' in contemporary debate on global urbanism (Brenner and Schmid 2015), but rather to situate the topic of the built heritage in such a discussion. This will provide a two-fold benefit: on the one hand, to acknowledge that heritage is today increasingly considered an asset for development and therefore widely associated with processes of planetary gentrification (Lees, Hyun, and Lopez-Morales 2016). In other words, heritage and the built heritage can be studied in conjunction with the major process of agglomeration/ polarisation focusing on the risk associated with its relative scarcity in such a process; on the other hand, to recognise that, around notions of identity, memory, past, history and so on, different localities and local cultures are still arguing for different interpretations and therefore ways of action and transformation, often in open collision with the mainstream discourse. It is a gradual process of reinstating into the heritage field the legitimacy of other forms of civilisation (Braudel 1993) or, to a certain extent, of non-exploitative and non-functionalistic values even within the West. It is at the crossing of these two different processes of globallocal, North-South, East-West that tensions emerge in the urban realm, determining locally the need for mediation between global forces and local practices.

Coming back to the initial question posed here, as to whether planetary urbanisation matters for the built heritage, the response is based on the evidence that many historic areas are either strongly affected by urbanisation, with historic areas being physically destroyed, permanently altered and arbitrarily reconstructed or, when protected, sooner or later, by exploitative trends of gentrification. This is independent of their location. In support of this statement, it is worth adding that planetary urbanisation refers to a global condition where the urban is no longer 'a bounded, nodal and relatively self-enclosed socio spatial condition' but rather a more 'territorially differentiated, morphologically variable, multiscalar and processual conceptualisation' (Brenner 2014, 15). Drawing on Lefebvre's (2003) radical hypothesis of the complete urbanisation of society, Brenner and Schmid $(2012,13)$ argue that 'this situation of planetary urbanisation means, paradoxically, that even spaces that lie well beyond the traditional city cores and suburban peripheries ... have become integral parts of the worldwide urban fabric'. Assuming this as true, such a pervasive process determines the transformation of historic districts, no matter if in the city or in remote rural villages, mostly into theme parks in the service of a global consumerist elite. The variety of examples in this respect is very wide, featuring various degrees of the so-called Disneyfication process. For example: (1) a combination of residential displacement and tourism development can be found in areas as diverse as the former French Concession of Shanghai, the Casco Antiguo of Panama and the Ciutat Vella of Barcelona; (2) massive flows of tourists, well beyond the local carrying capacity, affect, on a daily basis, cities such as Venice in Italy or rural villages such as Tongli in the Jiangsu Province of China; similarly, people move (en masse) from Tokyo to the Mizusawa Udon Village in Gunma Prefecture in search of one of the most famous Udon noodles of Japan (Kim and Iwashita 2016). As a consequence, besides the obvious effort to restore and protect the built heritage to serve this mono-functional demand, local policies for clearing and beautification are frequently implemented for improving local attractiveness. This is the case with the historic centre of Quito in Ecuador, where a zero-tolerance policy against street vendors and other informal activities has long been in place (Swanson 2007), or the notorious case of New York, followed by other cases such as the historic centre of Bologna in Italy, where long-lasting 'wars' against graffiti have been conducted (Iveson 2010). In the same vein, in China national policies were recently released to rescue heritage buildings from apparently dangerous functions like restaurants and bar, with immediate effect on the urban landscape (Figure 3a, Figure 3b).

While the examples here reported draw an undeniable linkage between 'planetary urbanisation' and 'planetary gentrification' of the built heritage, which might certainly be regarded as the mainstream trend, this is not sufficient to explain the variety of conditions found in cities today. First and foremost, there are still historic areas that have not been affected by these processes as they are simply isolated by the globalisation process. There are cities affected by wars, permeated by strong religious beliefs, controlled by dictatorial regimes and so on, that simply cannot take part in such a process. This can be just a temporary situation, as the post-Castro Havana in Cuba has sadly proved, and we might realistically expect in the future such cities 

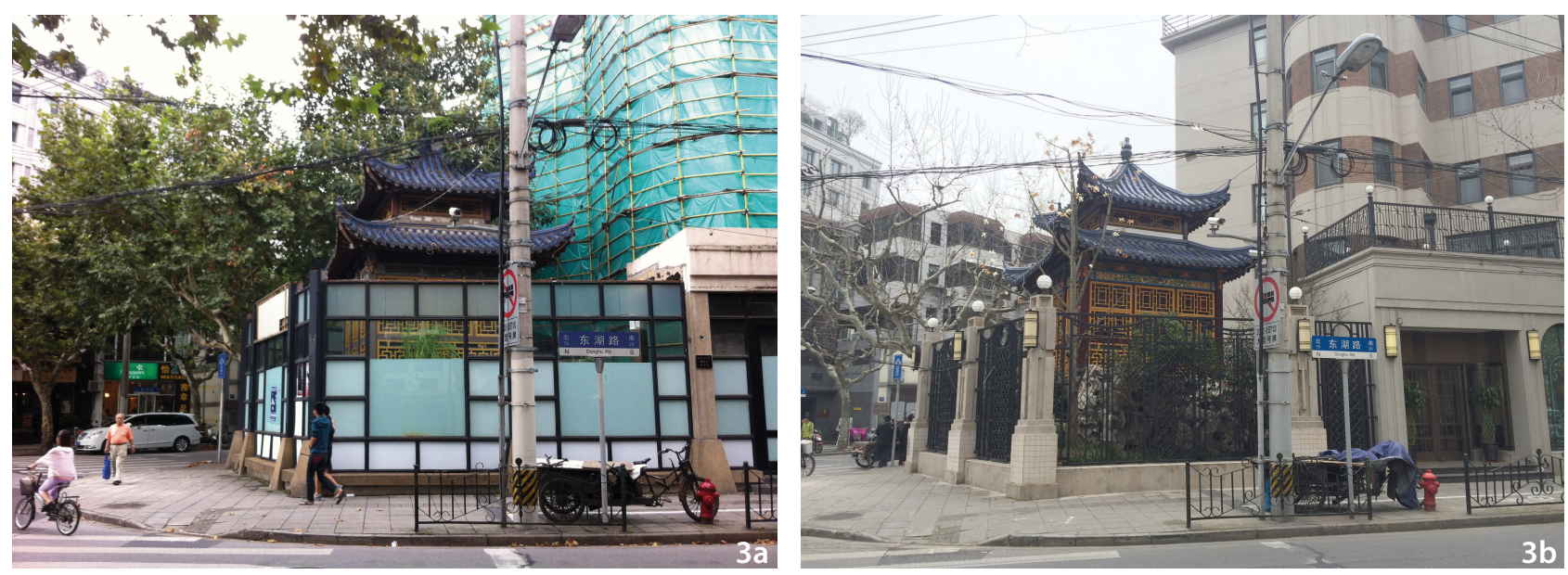

Figure 3a and 3b Shanghai, People's Republic of China. The temple in Donghu Road. 3a: the temple was previously located inside a restaurant, September 2014. 3b: the temple has been isolated as monument, in a clear process of Westernisation, March 2016. (Source: the author).

as Pyongyang in North Korea or Kabul in Afghanistan to enter this condition.

However, and more interestingly, there are a number of other cases, that fall outside this simple categorisation. There are places that are marginal in respect to global gentrification processes, being not located at the core of agglomeration processes. Despite their location, they retain a historic identity and a certain local dynamism, having developed their own niche economic system, as reported in recent research on historic small settlements in Asia, South America and Europe (Verdini and Ceccarelli 2017). These towns survive despite their peripherality, being either rural villages, part of dispersed territorial formations or informal settlements enclosed in large, urban agglomerations. Their built heritage is a component of the overall local economic life, but it is not at its core.

There are also cases that are managed and planned not solely in response to major global economic forces. The way the city is organised, and the way the legacy of the past is treated, protected or deliberately not even considered as part of local identity, is instead responding to local motives and alternative systems of beliefs and practices profoundly rooted in different cultural contexts. Therefore, they utilise different tools and methods for management and conservation. Although still not very rich and systematic, there is an increasing body of literature in English showing these differences. Japanese urbanism is different in essence from that of the West, being the pattern of a city more decentralised, patchy, temporary, flexible, vague (in opposition to the traditional Western one, which is more centralised, networked, permanent, fixed and clear), to cite just a few adjectives (Shelton 2012, 129). Chinese cities are even more diverse and their approach to the past and the built heritage has been effectively associated by Li (2014) with the idea of 'memory without location' in opposition to the great Western emphasis given to the city as a physical archive of memories. This can justify, for example, the practice of reconstruction in China, being interpreted as expression of 'immaterial authenticity'. Similarly in India, the Indian National Trust for Art and Cultural Heritage states in its adopted Charter that 'In consonance with traditional ideals, replication can be accepted as an appropriate strategy not only to conserve unprotected historic buildings, but especially if such replication encourages historic ways of building' and 'Reconstruction based on minimal physical evidence is appropriate where it is supported by the knowledge of local craftspeople, including folklore, beliefs, myths and legends, rituals, customs, oral tradition etc.' (INTACH 2004)

In summary, while heritage and local cultures are surely scarce resources within the process of urban agglomeration, they might not necessarily play the same role, or be treated in the same way in cities. It is for this reason that, similar to what 'comparative urbanism' has attempted to unveil in urban theory, a non-Western approach to the built heritage seems to provide a necessary and more nuanced understanding of the global conservation practice today. In light of the introductory part on the role that culture has assumed in international agendas on sustainable urbanisation, this will allow, in the discussion and conclusion, confronting the reality of daily practices in many parts of the world with the international discourse on culture and heritage to unfold overlaps and discrepancies. 


\section{Non-Western Cases and Post-colonial Debates around the Built Heritage}

Non-Western approaches in the field of urban studies are related to urban models that do not necessarily fit into the Western paradigm of the 'industrial civilisation'. Such a form of civilisation is related to modern colonialism as perpetrated by Europe in the $19^{\text {th }}$ and early $20^{\text {th }}$ century (Loomba 1998). Therefore, for the scope of this article, the label 'non-Western' will be primarily associated with the resurgence of interest for alternative systems in postcolonial studies. This will prevent us from falling into reading the entire Western culture as an imposition, overlooking the processes of mutual learning always existed between the East and the West (Shan 2016). The alternative non-Western approaches here mentioned do not comply entirely with the mainstream model of urban accumulation of resources. This model consists primarily in the set of urban policies historically employed to manage a process of linear accumulation, characterised by countryside-to-city migration processes, and embodied in the traditional, centralised and comprehensive urban-planning approach exported to cities of the global South. Consequently, in the field of heritage studies, the notion of heritage itself has assumed a specific connotation. In the West, heritage is largely related to the legacy of the Industrial Revolution, where the definition of 'historic monuments' and consequently the idea of urban conservation arose. The brutality and the speed of transformation of this process have influenced the debate around the modern concept of heritage and obsession for its physical protection, especially in England and France in the early $19^{\text {th }}$ century (Choay 1992). This will later generate a wider intellectual movement advocating for the protection of the tangible forms of the past. Understandably, the aggravation of the physical damages of the two World Wars, which mostly affected the developed world, imposed a new international agenda for the protection of cultural properties, developed in the second half of the $20^{\text {th }}$ century. This has materialised in the adoption of the International Charter for the Conservation and Restoration of Monuments and Sites (the Venice Charter) in 1964, culminating few years later in the approval of the UNESCO World Heritage Convention in 1972 (Cameron and Rössler 2013).

However, in recent years, the consensus around the need to protect heritage and to employ the tools to preserve its physical integrity and ultimately its supposed authenticity has changed. Interestingly, the discussion around the need to redefine the boundary of the heritage discipline has been driven primarily by attempts to reinterpret heritage as a process rather than as an object, rediscovering its pre-modernist roots (Harvey 2001). It was common practice in the past to reuse quite freely structures and materials readapting the past to modern functions, as happened with the Thermae of Diocleziano, the ancient roman baths converted by Michelangelo into the church of S. Maria degli Angeli in the middle of the $16^{\text {th }}$ century. The long-lasting international discussion on the protection of cultural landscape has also shifted attention to the dynamic relations between man and nature, with interesting convergences between Western and Asian approaches (Taylor and Lennon 2011). However, it is mainly around the notion of authenticity of heritage that the hegemonic power of Western values and beliefs in the heritage field has emerged. This was openly challenged by the Nara Document on Authenticity in 1994, where Asian scholars (with the particular engagement of the Japanese ones) have advocated for reconsideration of Asian approaches to materiality beyond the dogmatic assumptions of the Venice Charter. The Nara Document was 'a tacit acknowledgement of the plurality of approaches to the issue of authenticity ... [which] does not reside primarily in Western notions of intact fabric' (Taylor 2004, 430).

This debate is rooted in the deep difference between the East and the West, as highlighted by Braudel $(1993,169)$ :

What we must try to understand, forgetting our Westerners' experience, is that the two great civilisations of the Far East are thousands of years old. In the Far East monuments deteriorate and decay all too quickly, in so far as they are often made of fragile materials, as in China and Japan. Human society and culture, by contrast, seem indestructible. ... Hinduism, still very much alive, has been the almost unaltered basis of the Indian civilisation for more than a thousand years. ... In China, the cult of ancestors and of the gods of nature, which dates from at least the first millennium BC, has continued in Taoism, Confucianism and Buddhism. ... These ancient and tenacious religious systems are linked with social structures which are no less hardy, castes in India, family and social hierarchies in China. ... Unlike the West, which clearly separates the human from the sacred, the Far East makes no such distinction.

This consideration stimulates a discussion on what should be really protected, whether it should, and, in that case, which criteria should be applied in a non-Western context. It is the case of China where the recent resurgence of interest for the protection of extremely fragile structures such as the natural villages in rural areas has 
legitimised flexible conservation approaches (Zhu 2015). Moreover, the substantial diversity of social structures is another fundamental element to consider when dealing with heritage issues in the East and the West. This is today even more important than before, as the international conservation doctrine has expanded, including a different set of tools not explicitly contemplated before. It is the case of the UNESCO Recommendation on Historic Urban Landscape of 2011, that advocates for the application of an integrated approach to conservation including tools to foster, for example, civic engagement and public participation (UNESCO 2011). In a recent study aimed at reframing the theoretical boundary of the current urban conservation discourse in China, this element has resulted as being one the most controversial points for a meaningful application of the HUL approach in China, given the high level of social divide within communities (Verdini, Frassoldati, and Nolf 2016).

It is not surprising considering that the concept of community and citizenship derives from the civic traditions of the ancient polis and commune of the Middle Ages in Europe, while being almost absent historically in Asian cities. The ideal-type of the city depicted by Weber in 'Wirtschaft und Gesellschaft' (1978), differs from cities in India, China and Japan where associations or guilds were not linked to the right of citizenship but people, despite their association in corporations, were still attached to their original village, caste, clan and so on. Without entering into a debate on whether the idea of the polis is still applicable in Europe or the West in general, given the high level of social fragmentation and diversity within communities, it is by no means a factor that can be underestimated in repositioning the debate on heritage and its conservation in a non-exclusively Western context.

This brief consideration on the East-West dualism suggests that an increasing multiplicity of perspectives exists around the notion of heritage with a direct implication on the tools in use to protect it. The non-materiality of heritage and its spiritual dimension has been probably one of the most convincing arguments to challenge the official doctrine and it has found responses in additional official conservation documents. One example is the establishment of the List of Intangible Cultural Heritage in 2008, as a result of the 2003 Convention for the Safeguarding of the Intangible Cultural Heritage. It is not a coincidence that the majority of cases in the list are from countries like China, India, Japan, Korea and Vietnam.

More controversial is instead the fact that most of the historic artefacts today unanimously considered worthy of protection are colonial buildings or urban colonial ensembles, especially in Africa and South and Central America. Despite the attempt to foster a consensual past, especially from international agencies such as UNESCO, and to mitigate the potential conflict inherent in certain sites by developing uniform narratives (Vahtikari 2017), some local conflicts remain de facto unanswered. This is the case with the already mentioned historic centre of Quito in Ecuador, which was listed as a UNESCO World Heritage in 1978 as being a unique example of South American Baroque. Since 2003, the capital city has been the object of a vast renewal project, comprising specific policies to revive the city centre and to attract tourism and global investment (Middleton 2003). A specific target of this policy was the regulation of indigenous street vendors and beggars, mainly coming from the surrounding villages and affected by programmes of agriculture restructuring (Swanson 2007). While the potential conflicts between the new, wanted image of the city and the informal use of the space are evident, such policy tends to replicate a colonial logic that perceives the indigenous people as extraneous from the daily life of the city, pushing them away from the sanitised central areas of the city. However, their presence is paradoxically an element of the conflictive urban landscape and identity that colonial cities had and still have, posing a question of what is really authentic in such contexts (Figure 4a, Figure 4b). Similar approaches might be found even more recently in cities as diverse as Mexico City, with the 'Rescue Programme' of the historic city centre (Crossa 2009), or in Guangzhou in China, with the 'Forbidden Area for Street Vendors' warning issued by the Urban Management Authority in 2010 (Huang, Xue, and Li 2014). However, the case in Guangzhou shows an ambivalent and more pragmatic approach, as it tends to regulate the phenomenon excluding informal street vendors just from some key representative areas, such as 'the administration area (in historical city centre), city parks, CBD, the exhibition centre and train stations' (184). Nevertheless, the built heritage seems to be excluded from any form of real-life activities, as if it should be isolated from the real functioning of the city.

The tension between orderly and informal, clean and unregulated, planned and random, which is the legacy of modernism, finds correlations with the contrasts between the Western and Chinese/Asian thought highlighted by the French philosopher, Francois Jullien. In his recent work De l'etre au vivre (2015) he points out the tendency of Western thought, since Aristotle, to rely on models and to conceive the entire essence of reality as a consequence 

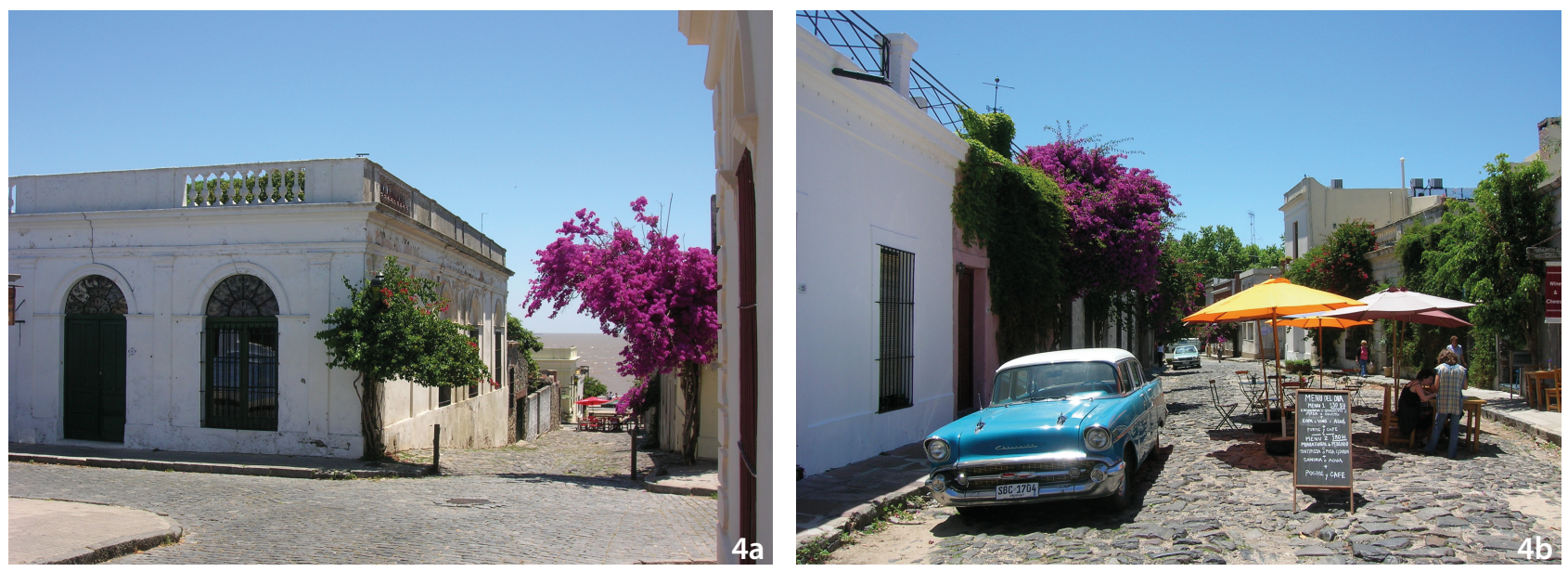

Figure 4a and 4b Colonia del Sacramento, Uruguay, 2005. The gentrification of the colonial historic centre, with the opening of restaurants and hotels, which is very common in colonial cities of South America (Source: the author).

of its ideal configuration. Conversely, Chinese thought conceives of reality as a gradual maturation, much more related to the organic rhythms of nature. It is evident in the different approaches of the 'Art of War', where decisions are contextually taken based on situations, rather than strategically defined a priori. This has an influence on the way Chinese and Asian cities function and it is used by Jullien to depict the paradoxical situation whereby the traffic in Asian cities is not (only) formally regulated by traffic lights but, due to the huge number of vehicles in the street, by collective customs and informal behaviours, which result in being very effective despite the apparent chaos. The thought-provoking metaphor of the orderly chaos of Asian cities is an intellectual stimulus to reflect on whether the Western models of cities and, consequently, the way of protecting the past utilised over the last two centuries are still entirely valid today.

\section{Discussion and Conclusion}

This paper has highlighted the uneasy relationship between the speed and scope of contemporary planetary urbanisation and the transformation of both the built heritage and local cultures. While advocacy for the protection of culture (what we should protect), in both its tangible and intangible expressions, is increasingly central to international agendas on sustainable urbanisation, this paper has argued that the ultimate reason for doing it and, consequently, the tools for its protection, are subject to intense debate and, in some cases, reconsideration.

It is at least since the 1990s that alternative, nonWestern and primarily non-materialistic approaches to heritage have emerged in the international arena, determined by the firm position taken by Asian countries to redefine the principles of the international doctrine of conservation. As a matter of fact, this doctrine relies today on what de facto has been legitimately and multilaterally negotiated in the so-called international diplomacy of heritage (Winter 2015). Therefore, even if it still reflects a core of 'European' values, around notions of buildings and monuments conservation, it incorporates wider perspectives on protecting and managing, in a sustainable way, communities, cultural landscapes, traditional knowledge and so on (Winter 2014).

In addition to that, the paper has explored the ambiguous nexus between planetary urbanisation and culture, in particular around the question of 'deterritorialised and transient' local communities and the scarcity of built heritage. The former issue impacts on some of the assumptions at the basis of the conservation doctrine, namely the supposed coherency and authenticity of places and communities and, consequently, on the effectiveness of tools such as community participation and civic engagement. The latter determines instead exploitative practices of heritagisation, which have been here associated with planetary gentrification processes. It is not uncommon (and it will be even more the case in the future), that the process of protection itself is a precondition for social exclusion and spatial fragmentation, whether in Western or Asian countries. The divide will be even fiercer, especially if applied to former colonial heritage sites, where inherent conflictive narratives are still far from being reconciled, from Quito in Ecuador to Ho Chi Minh in Vietnam.

Therefore, the underlying argument of this paper is that the sense of inadequacy of the existing tools for 
conservation is not dependent on a simplistic East-West divide, but is instead more generally linked to the sense of failure of the 'industrial civilisation' exported by the West during the colonial period and once assumed as universal. This supports consequently the advocacy for the acknowledgement of a pluralism of practices and the contributions of other civilisations to the discussion of what is worth being protected. It ultimately poses the question of why, and consequently, how we should protect the past.

Post-colonial urban studies have attempted to move from a narrow application of universalistic principles to urban development by looking at non-Western countries. It is still a field of investigation that requires the consolidation of a more critical body of knowledge, but it has also already traced some intriguing research directions. It is even more so for the broad topic of the conservation of the past. Besides the institutionalised international conservation doctrine, the process of planetary urbanisation determines frictions between the current practice and the legitimate, although sometimes controversial, claims of those who refer to other forms of civilisation (nonWestern) and to non-exploitative and non-colonialist systems of conservation.

Planetary urbanisation imposes the need to acknowledge a pluralism of practices in the discussion of what is worth protecting and how to achieve this. The new journal Built Heritage could play a significant role in the years to come in two main directions in the field of urban conservation:

- To give voice to non-Western practices of conservation, particularly looking at China, India and Japan, without a Western bias and without necessarily assessing their outcomes against Western experiences;

- To give voice to non-exploitative practices of conservation both in the West and in post-colonial countries, rooted in a long, pre-modern tradition of dynamic transformation of the past, largely antithetical to the more recent and 'modern' heritage 'objectivisation';

These research directions should feed into an alternative critical-research agenda for sustainable urban development, which is still too much driven by an underlying neo-liberal ideology and which is still overreliant on data and examples coming from Western countries. The ultimate goal would be to rethink a post-colonial approach to urban conservation to ensure pluralism and wider democratisation of the conservation doctrine. This is a fundamental step toward reassessing non-Western practices in a fairer way. This might be also regenerative for the West itself, too often relying on obsolete and overexploitative models of conservation of the built heritage.

\section{References}

Appadurai, A. 1996. Modernity at Large: Cultural Dimensions of Globalization. Minneapolis: University of Minnesota Press.

Batuman, B. 2013. "City Profile: Ankara." Cities 31: 587-590.

Braudel, F. 1993. A History of Civilizations. Translated and edited by Richard Mayne. London: Penguin Books.

Brenner, N., and C. Schmid. 2012. "Planetary Urbanization." In Urban Constellations, edited by M. Gandy, 10-13. Berlin: Jovis.

Brenner, N., ed. 2014. Implosions/Explosions: Towards a Study of Planetary Urbanization. Berlin: Jovis.

Brenner, N., and C. Schmid, 2014. "The 'Urban Age' in Question." International Journal of Urban and Regional Research 38(3): 731-755.

Brenner, N., and C. Schmid. 2015. "Towards a New Epistemology of the Urban?” City 19(2-3): 151-182.

Burdett, R., and P. Rode. 2010. “The Urban Age Project.” In The Endless City, edited by R. Burdett and D. Sudjic. London: Phaidon.

Cameron, C., and M. Rössler. 2013. Many Voices, One Vision: The Early Years of the World Heritage Convention. Farnham: Ashgate.

Choay, F. 1992. Lallegorie du patrimoine [The Allegory of Heritage]. Paris: Editions du Seuil.

Clark H. 2011. "The Fall of Saigon-by Demolition" The Independent, January 12. Accessed 23 June 2017. http://www. independent.co.uk/news/world/asia/the-fall-of-saigonndash-by-demolition-2182182.html

Crossa, V. 2009. "Resisting the Entrepreneurial City: Street Vendors' Struggle in Mexico City's Historic Centre." International Journal of Urban and Regional Research 33(1): 43-63.

González Martínez, P. 2016. "Authenticity as a Challenge in the Transformation of Beijing's Urban Heritage: The Commercial Gentrification of the Guozijian Historic Area." Cities 59: 48-56.

Harvey, D. 2001. "Heritage Pasts and Heritage Presents: Temporality, Meaning and the Scope of Heritage Studies." International Journal of Heritage Studies 7(4): 319-338.

Huang, G., Xue D., and Z. Li. 2014. "From Revanchism to Ambivalence: The Changing Politics of Street Vending in Guangzhou." Antipode 46(1): 170-189.

International Council on Monuments and Sites (ICOMOS). 1987. Charter for the Conservation of Historic Towns and Urban Areas. Washington, United States. Accessed 23 June 2017. https://www.icomos.org/charters/towns_e.pdf

Indian National Trust for Art and Cultural Heritage (INTACH). 2004. Charter for Conservation of Unprotected Architectural 
Heritage and Sites in India. New Delhi, Indian. Accessed 23 June 2017: http://www.intach.org/about-charter.php

Iveson, K. 2010. "The Wars on Graffiti and the New Military Urbanism." City 14(1-2): 115-134.

Jullien, F. 2015. De l'etre au vivre. Lexique euro-Chinois de la pensée [To Be or to Live. Sino-European Lexicon of Thought]. Paris: Editions Gallimard.

Kim, S., and C. Iwashita. 2013. "Cooking Identity and Food Tourism: The Case of Japanese Udon Noodles." Tourism Recreation Research 41(1): 89-100.

Lees, L, Hyun, B. S. and E. Lopez-Morales. 2016. Planetary Gentrification. Cambridge: Polity Press.

Lefebvre, H. 2003. The Urban Revolution. Translated and edited by R. Bononno. Minneapolis: University of Minnesota Press.

Li, S. 2014. Understanding the Chinese City. Thousand Oaks, CA: SAGE.

Loomba, A. 1998. Colonialism/Postcolonialism. New York-London: Routledge.

Middleton, A. 2003. "Informal Traders and Planner in the Regeneration of Historic City Centres: The Case of Quito, Ecuador." Progress in Planning 59(2): 71-123.

Parnell, S., and E. Pieterse. 2015. “Translational Global Praxis: Rethinking Methods and Modes of African Urban Research." International Journal of Urban and Regional Research 40(1): 236-246.

Robinson, J. 2006. The Ordinary City: Between Modernity and Development. London: Routledge.

Robinson, J. 2016. “Comparative Urbanism: New Geographies and Cultures of Theorizing the Urban." International Journal of Urban and Regional Research 40(1): 187-199.

Roy, A. 2011. "Slumdog Cities: Rethinking Subaltern Urbanism." International Journal of Urban and Regional Research 35(2): 223-238.

Roy, A. 2016. "Who's Afraid of Postcolonial Theory?" International Journal of Urban and Regional Research 40(1): 200-209.

Satterthwaite, D. 2010. "Urban Myths and the Mis-Use of Data that Underpin Them." In Urbanization and Development, edited by J. Beall, B. Guha-Khasnobis and R. Kanbu. Oxford: Oxford University Press.

Shan, S. 2016. "Introduction: The Last Post." In Critical Muslim 20 (Special Issue: Postwest): 3-18.

Scott, A. J., and M. Storper. 2014. "The Nature of Cities: The Limits and Scope of Urban Theory." International Journal of Urban and Regional Research 39(1): 1-15.

Shelton, B. 1999. Learning from the Japanese City: West meets East in Urban Design. New York: Routledge.

Swanson, K. 2007. "Revanchist Urbanism Heads South: The
Regulations of Indigenous Beggars and Street Vendors in Ecuador." Antipode 39(4): 708-728.

Taylor, K. 2004. "Cultural Heritage Management: A Possible Role for Charters and Principles in Asia." International Journal of Heritage Studies 10(5): 417-433.

Taylor, K., and J. Lennon. 2011. "Cultural Landscapes: A Bridge between Culture and Nature?" International Journal of Heritage Studies 17(6): 537-554.

UNESCO. 2011. Recommendation of the Historic Urban Landscape. Paris: UNESCO.

UNESCO. 2016. Culture: Urban Futures; Global Report on Culture for Sustainable Urban Development. Paris: UNESCO.

United Nations. 2015a. World Urbanization Prospects: The 2014 Revision. New York: UN Department of Economic and Social Affairs, Population Division.

United Nations. 2015b. “Transforming Our World: The 2030 Agenda for Sustainable Development." Resolution Adopted by the General Assembly of the United Nations on 25 September 2015. New York: United Nations.

Vathikari, T. 2017. Valuing World Heritage Cities. New York: Routledge.

Verdini, G. 2015. "Is the Incipient Chinese Civil Society Playing a Role in Regenerating Historic Urban Areas? Evidence from Nanjing, Suzhou and Shanghai." Habitat International 50: 366-372.

Verdini, G. and P. Ceccarelli. 2017. Creative Small Settlements. Culture-Based Solutions for Local Sustainable Development, Research Report. London: University of Westminster.

Verdini, G., Frassoldati F., and C. Nolf. 2016. "Reframing China's Heritage Conservation Discourse. Learning by Testing Civic Engagement Tools in a Historic Rural Village." International Journal of Heritage Studies 23(4): 317-334.

Weber, M. 1978. Economy and Society. Translated by G. Roth and C. Wittich. Los Angeles: University of California Press.

Winter, T. 2014. "Beyond Eurocentrism? Heritage Conservation and the Politics of Difference." International Journal of Heritage Studies 20(2): 123-137.

Winter, T. 2015. "Heritage Diplomacy." International Journal of Heritage Studies 21(10): 997-1015.

Yassin, N. 2012. “City Profile: Beirut." Cities 29(1): 64-73.

Zhang, Y., and K. Fang. 2004. "Is History Repeating Itself? From Urban Renewal in the United States to Inner-City Redevelopment in China." Journal of Planning Education and Research 23(3): 286-298.

Zhu, Y. 2015. "Cultural Effects of Authenticity: Contested Heritage Practices in China." International Journal of Heritage Studies 21(6): 594-608. 